\title{
NEWER DIMENSIONS IN THE EVALUATION OF PELVIC PATHOLOGY BY TRANSPERINEAL ULTRASONOGRAPHY
}

\author{
S. C. Sanjay ${ }^{1}$, N. Krishnappa ${ }^{2}$, Anil Kumar Shukla³
}

\section{HOW TO CITE THIS ARTICLE:}

S. C. Sanjay, N. Krishnappa, Anil Kumar Shukla. "Newer Dimensions in the Evaluation of Pelvic Pathology by Transperineal Ultrasonography". Journal of Evolution of Medical and Dental Sciences 2014; Vol. 3, Issue 18, May 05; Page: 4944-4955, DOI: 10.14260/jemds/2014/2536

ABSTRACT: BACKGROUND: Pelvic floor dysfunction is one of the common conditions encountered in female patient's especially uterine descent; cystocele and rectocele are faced by elderly parous women. At present there is no fixed ultrasound criteria to evaluate the pelvic floor. About $11-15 \%$ of the general populations who attend outpatient department suffer from various degrees of these problems. Ultrasound imaging of pelvic floor will help the patient from unnecessary complications and reduce the morbidity by delineating pelvic floor anatomy with dynamic studies. OBJECTIVES: To define pelvic floor ultrasound anatomy and to define fixed criteria for diagnosis of problems by 2D ultrasound and to apply the same to qualify and quantify problems. METHODS: Prospective ultrasonographic analysis of sequentially selected 50 cases presenting with pelvic floor dysfunction, and diagnosed clinically by gynecologists were included. INTERPRETATION AND CONCLUSION: Ultrasound is an invaluable, minimally invasive, highly accurate and cost effective procedure for assessment of pelvic floor movement of uterus, bladder and rectum with strain is best assessed on real time ultrasound.

KEYWORDS: Ultrasound, Uterine descent, Bladder neck descent, Cystocele, Enterocele and Rectocele.

INTRODUCTION: Pelvic floor weakness and organ prolapse is relatively common condition in middle aged and elderly parous women that can have a significant impact on quality of life.1, 2 Pelvic organ prolapse typically demonstrates multiple abnormalities and may involve uterus, the urethra, bladder, vaginal vault, rectum and small bowel. Patients may present with pain, pressure, urinary and fecal incontinence, constipation, urinary retention and defecatory dysfunction. Till date diagnosis was made primarily on the basis of findings at physical pelvic examination and history. ${ }^{2} \mathrm{New}$ imaging technology offers an opportunity to objectively assess the pathology and improve our follow up of patients and so obtain a better estimation of the true incidence of unsuccessful operations and postoperative complication.

High resolution dynamic transperineal ultrasound provide superior depiction of the pelvic anatomy and also help in understanding pathologic and functional changes that occur in pelvic floor disorders. Ultrasound has found more widespread use which provides excellent resolution and contrast, because of cost and it also offers a degree of dynamic imaging that is not currently achievable by other modalities. B mode ultrasonography is universally available and provides for real time observation of maneuvers such as valsalva and pelvic floor muscle contraction. We have seen 50 cases and were able to delineate various abnormalities.

METHODS: To start with we have to understand basics of ultrasound technique which will be possible only if we are able to simplify the anatomy. The use of transabdominal ultrasound in the evaluation of lower urinary tract and pelvic floor dysfunction was first documented in the early 
1980's with translabial, transrectal, and transvaginal technique developed somewhat later. 3,4,5 In our study, we intend to limit ourselves to transperineal (translabial, introital) imaging as first described in 1986. The study is a prospective study. The equipment used is state of art GE VOLUSON 730 PRO ultrasound machine with curvilinear high density multi frequency probe.

We included all women attending gynecological outpatient between the ages of 20 to 60 years with history of pelvic floor disease. We have excluded pregnant and nulliparous women. We have evaluated 50 cases of pelvic floor dysfunction like cystocele, uterine descent, rectocele.

Imaging was performed in dorsal lithotomy position with the hips flexed and slightly abducted. Imaging was done at rest and after valsalva. Partial bladder filling is necessary to look for the bladder neck. Descriptive statistical analysis has been carried out in the present study. Fisher exact test has been used to find the significance of study parameters on categorical scale between two or more groups. (Table 1).

To image a midsagittal view of the pelvic floor, the transducer is placed on the perineum of the patient after covering it with a condom /glove or thin plastic wrap for hygienic reasons. ${ }^{6}$ Prior voiding is preferable along with bowel emptying. Tissue discrimination is best in pregnancy and poorest in menopausal women.

The symphysis pubis should appear $<1 \mathrm{~cm}$ from the transducer surface which signifies that the labia have been displaced laterally by the transducer improving imaging conditions. Manual parting of the labia before transducer placement may be necessary especially if they are hypertrophic or particularly hirsute. The standard midsagittal field of vision includes the symphysis pubis anteriorly, the urethra and bladder neck, the vagina, cervix, rectum, and anal canal. Posterior to the anorectal junction, a hyperechogenic area indicates the central portion of the levator plate i.e. the puborectalis, pubococcygeus or pubovisceral muscle (Fig. 1).

The cul-de-sac may also be seen, filled with a small amount of fluid, echogenic fat or peristaltic small bowel. This implies that striated muscle or tubular structures such as the urethra may appear hypo, iso or hyperechoic depending on transducer orientation. In practice this is most relevant as regards to the urethral rhabdosphincter which appears hyperechoic on translabial ultrasound. (Fig. 1)

Thorough knowledge of the normal support anatomy is therefore essential to diagnose and treat pelvic floor dysfunction. ${ }^{7}$ Normal physiological function of the pelvic organs depends on the anatomic integrity of the support components. Pelvic support defects may contribute to pelvic organ prolapse, urinary and anal incontinence, sexual, voiding, and defecatory dysfunctions. ${ }^{7}$ The aim of this study is to describe the ultrasonic pelvic support anatomy and demonstrate various anomalies. The pelvic organs, pelvic floor muscles, and connective tissue of the pelvis attach to and are ultimately supported by the bony pelvis. The pelvic skeleton also constitutes the major mechanism for transmitting the weight of the trunk and upper limbs to the lower limbs.

During pregnancy the symphysis pubis and the ligaments of the sacroiliac and sacrococcygeal joints undergo softening in response to hormones thus increasing the mobility and the potential size of the pelvis during childbirth. Estrogen, progesterone, and relaxin are the hormones believed to contribute to these changes during pregnancy. The pelvis is divided into the greater also called as the "false" and the lesser or "true" pelvis by the plane of the pelvic brim. The true pelvis contains and supports the pelvic organs and has an inlet, a cavity, and an outlet. In the standing position the plane 
of the inlet makes an angle of $55^{\circ}$ to $60^{\circ}$ with the horizontal plane while the plane of the outlet makes a $15^{0}$ to $20^{\circ}$ angle.

Ligaments of the pelvis are sacrospinous, sacrotuberous, and anterior longitudinal ligament of the sacrum and they contribute to the stability of the bony pelvis. The iliopectineal (Cooper's) ligament a thickening in the periosteum of the pubic bone is used to anchor the sutures in the Burch retropubic bladder neck suspension. The round and broad ligaments connect the uterus and adnexa to the pelvic walls they do not contribute to the support of these organs.

The muscles that span the pelvic floor are collectively known as the pelvic diaphragm. This diaphragm consists of the Levator Ani (LA) and coccygeus muscles along with their superior and inferior investing layers of fasciae. Inferior to the pelvic diaphragm the perineal membrane and perineal body also contribute to the pelvic floor. Levator ani muscle is the most important muscle in the pelvic floor and represents a critical component of pelvic organ support. The normal levators maintain a constant state of contraction thus providing an active floor that supports the weight of the abdominopelvic contents against the forces of intraabdominal pressure. ${ }^{8}$ This action is thought to prevent constant or excessive strain on the pelvic "ligaments" and "fascia".

The LA muscle is a complex unit. The pubococcygeus, puborectalis, and iliococcygeus are the 3 components of the muscle. Knowing the precise attachments, function and innervations of each of the LA component allows better understanding of stress incontinence and lengthening of the uro genital hiatus. Different innervation of the levators and the triated urethral and anal sphincters may explain why some women develop pelvic organ prolapse and others develop urinary or fecal incontinence.

RESULTS: The present study was conducted over a period of 2 years with aim of assessing symptomatology, clinical presentation and ultrasound findings of pelvic floor dysfunction. The earliest parameter examined by transperineal ultrasound is bladder neck mobility. Bladder neck position and mobility can be assessed with degree of reliability. Points of reference are the central axis of symphysis pubis or its infero-posterior margin. In our study we have taken infero-posterior margin of the pubic symphysis as the reference point. A straight line is drawn down wards from the inferior pubic symphysis and named $A$. The bladder neck is identified and a perpendicular line is drawn to join the line A which is named as B. Measurements of bladder neck position relative to the symphysis pubis are generally performed at rest and on maximal valsalva maneuver the difference yields a numerical value for bladder neck descent.

There is no definition of normal or abnormal for bladder neck descent although cut off of 15 , 20 and $25 \mathrm{~mm}$ have been proposed to define hyper mobility in one study and 5.1- $5.3 \mathrm{~mm}$ in another study. Minimum BND (Bladder Neck Descent) was $0.20 \mathrm{~mm}, 25^{\text {th }}$ percentile $5.4 \mathrm{~mm}$ Median $9.5 \mathrm{~mm}$ $75^{\text {th }}$ percentile, $13.4 \mathrm{~mm}$ Maximum BND was $25 \mathrm{~mm}$. We have taken 9.5 to $13.4 \mathrm{~mm}$ as the standard level which suggests that bladder neck movement from 9.5 to $13.48 \mathrm{~mm}$ is significant and to be termed as bladder neck descent. (Table 2, 3)

When compared with home delivery, lower segment caesarian section (LSCS) and institutional delivery. LSCS has more bladder neck descent followed by normal delivery and home delivery respectively, which suggests that connective tissue disorders also contribute to bladder neck descent. The low measurements of minimum bladder neck descent, rectocele, uterine descent could be attributed to the fact that if the patient does not perform good valsalva. The central and posterior 
compartment prolapse quantification was done in the following manner. The inferior margin of symphysis serves as a convenient point of reference against which the maximal descent of the bladder, uterus (cervix) and rectal movements can be measured.

The bladder neck of the leading edge of a cystocele is used for quantification of anterior vaginal wall descent, the cervix for the central compartment and the most caudal aspect of the rectal ampulla or the leading edge of the rectocele contents for quantification of posterior compartment descent. In our study we have made an attempt to measure the movement of the uterus and rectum at rest and valsalva maneuver keeping the inferior pubic bone as the reference and to quantify the cut off for uterine descent and rectocele.

In our study of uterine descent we observed that mean was $13.25 \mathrm{~mm}, 25^{\text {th }}$ percentile is $8.2 \mathrm{~mm}$, median is $14.8 \mathrm{~mm}, 75^{\text {th }}$ percentile is $19.18 \mathrm{~mm}$ and maximum movement was $26.20 \mathrm{~mm}$. We have taken $14.8 \mathrm{~mm}$ to $19.8 \mathrm{~mm}$ as the standard level of cut off which suggests that any patient with the cervix crossing the inferior pubic line and a movement of $14.8 \mathrm{~mm}$ to $19.5 \mathrm{~mm}$ can be termed as uterine descent. When compared with home delivery LSCS and institutional delivery patient with home delivery had more uterine descent followed by institutional delivery and LSCS respectively. (Table 4, 5).

In our study of rectocele we made following observations. Mean $10.9 \mathrm{~mm}$, minimum $0.2 \mathrm{~mm}$, $25^{\text {th }}$ percentile $2.6 \mathrm{~mm}$., median: $7.2 \mathrm{~mm}$, $75^{\text {th }}$ percentile $22.8 \mathrm{~mm}$.(Table 6) Maximum movement was $28.9 \mathrm{~mm}$. (Fig. 4).We have taken 2.8 to $5.8 \mathrm{~mm}$ as the standard level of cut off which suggests that any patient with the rectum crossing the inferior pubic line and the movement of 2.8-5.8 $\mathrm{mm}$ can be termed as rectocele.(Table 7)(Fig. 5, 6) When compared with home delivery LSCS and institutional delivery had more rectocele followed by home delivery and LSCS respectively. Enterocele is frequently over looked on clinical examination and its relation to pelvic floor symptoms remains unclear. With transperineal imaging it is relatively easy to detect enterocele by looking at the peristaltic activity.

In the present study maximum age recorded was 60 years and minimum was 33 years. As for the symptomatology of pelvic floor dysfunction are concerned most of the patients came for increased frequency of micturition, burning micturition, pelvic pain and uterine descent. Follow up of few cases that got operated were scanned to look for vault prolapse.

DISCUSSION: Imaging of the pelvic floor dates back to early 1920 by conventional radiography. From 1980 's trans abdominal, perineal, transrectal and transvaginal ultrasound have been investigated for use in women with urinary incontinence and prolapse. Because of its noninvasive nature, ready availability and the absence of distortion, perineal or translabial ultrasound is currently used most widely. ${ }^{9}$ Nygard in 1997 first studied stress incontinence more prevalent in high impact sports using Ultrasound. Eliasson in 2002 demonstrated the same. ${ }^{9}$ In 2006, Dietz HP demonstrated the pelvic floor imaging by ultrasound. In 2006 Purandare demonstrated the use of 3D and 4D ultrasound in rectovaginal septal defects.

It is likely that the etiology of pelvic organ prolapse is multifactorial and results from a combination of risk factors including pregnancy, multiparity, vaginal childbirth, aging hypoestrogenism, trauma, chronically increased intraabdominal pressure, nerve injury, smoking and prior surgery etc. The process of prolapse occurs over many years and risk increases 1.2 times with each vaginal delivery. Macrosomia, prolonged second stage of labor, episiotomy, anal sphincter 
laceration, epidural analgesia, forceps and oxytocin use have all been proposed as risk. The pelvic floor is exposed to compression and extreme pressures from the fetal head and maternal expulsive efforts.

It is theorized that when the levator ani muscle loses tone it drops form a horizontal to a semi vertical position, causing a widened or open genital hiatus that predisposes the pelvic viscera to prolapse. ${ }^{10}$ Without adequate levator ani support, the visceral fascial attachments of the pelvic contents are placed on tension and are thought to stretch and eventually fail. Direct injury to the levator ani muscles is believed to occur during the second stage of labor.

It has been shown through computer-simulated models that the medial pubococcygeus muscles undergo the most stretch. Tunn et al described the levator ani muscle after vaginal delivery in 14 women. $^{2}$ They found the urogenital and levator hiatus areas to be increased immediately postpartum compared with repeat scans 2 weeks later. Changes seen in slow twitch muscle after denervation include muscle necrosis with resultant atrophy and fibrosis.

The vaginal wall is atonic and the uterine supports are weak. The basic pathophysiology is by fascial and connective tissue weakness. These women have a high incidence of urinary incontinence. The site-specific defect theory is based on the premise that tears in the "endopelvic fascia" surrounding the vaginal wall allow herniation of the pelvic organs. Loss of normal vaginal support can be seen to some degree or another in as many as $43 \%$ to $76 \%$ of women. ${ }^{11}$

Symptoms that have commonly been attributed to pelvic organ prolapse are 1) Vaginal bulging, pelvic pressure. 2) Stress urinary incontinence or voiding dysfunction 3) Fecal incontinence 4) Chronic straining to defecate 5) Chronic back pain. Urinary symptoms like urethral hypermobility and cystocele formation, urgency, frequency, and urge urinary incontinence have been inconsistent in $23 \%$ to $50 \%$ of women. Studies estimate that $7 \%$ to $31 \%$ of women of pelvic organ prolapse also have symptoms of fecal incontinence. ${ }^{12}$

The anterior compartment imaging shows bladder neck position and mobility which is one of the earliest parameters to be examined by translabial ultrasound. Points of reference are the central axis of the symphysis pubis, or its inferoposterior margin. Measurements of bladder neck position relative to the symphysis pubis are generally performed at rest and on maximal valsalva maneuver. The difference yields a numerical value for bladder neck descent (BND) [Fig. 2]. On valsalva, the proximal urethra may be seen to rotate in a posteroinferior direction.

The other way to investigate is to measure the retrovesical (RVA) or posterior urethrovesical (PUV) angle between proximal urethra and trigone. It determines the angle between the central axis of the symphysis pubis and a line from the inferior symphyseal margin to the bladder neck. Of all those ultrasound parameters of hypermobility BND may have the strongest association with urodynamic stress incontinence (USI). (Fig 2)

There is no definition of normal for BND although cutoffs of 15,20 , and $25 \mathrm{~mm}$ have been proposed to define hypermobility, Mean values in women with stress incontinence are consistently around $30 \mathrm{~mm}$. Marked funneling has been shown to be associated with poor urethral closure pressures.

The most frequent finding in cases of bladder neck hyper mobility is descent of the internal meatus i.e. proximal urethra and trigone rotate around the symphysis pubis that is in a dorsocaudal direction. In such cases the retrovesical angle opens to up to $160-180^{\circ}$ from a normal value of 90 $120^{\circ}$ and such change in the retrovesical angle is generally associated with funneling. A cystocele 
with intact retrovesical angle $90-120^{\circ}$ is frequently seen in continent prolapse patients. Marked urethral kinking in patients with cystoceles can lead to voiding dysfunction and urinary retention. ${ }^{14}$ Descent of the bladder to $>10 \mathrm{~mm}$ below the symphysis pubis is strongly associated with symptoms of prolapse and has been proposed as constituting significant anterior compartment prolapse on the basis of receiver operator curve characteristics.

Indirect sings of urine leakage on B-mode real-time imaging are weak gray scale echoes (streaming) and the appearance of two linear (specular) echoes defining the lumen of a fluid filled urethra. Color doppler ultrasound has been used to demonstrate urine leakage through the urethra on valsalva maneuver or coughing. Routine sonographic documentation of stress incontinence during urodynamic testing clearly is feasible.

Urethra on translabial imaging is evident as a vertical hypoechoic area. Translabial ultrasound may be used to quantify uterovaginal prolapse. The inferior margin of the symphysis pubis serves as a convenient line of reference against which the maximal descent of bladder, uterus, cul-de-sac and rectal ampulla on valsalva maneuver can be measured. Because the hiatus on valsalva is generally too large especially in women with prolapse to allow for simultaneous imaging of the entire symphysis pubis and the posterior compartment, it is often not possible to use a line perpendicular to the central axis of the symphysis pubis as reference for descent of a rectocele or enterocele (Fig. 3).

Other findings like residual urine, urethral diverticula, labial cysts, vaginal fibroma, bladder tumor, intravesical stents and bladder diverticula can also be visualized. Postoperative hematoma may be visible after vaginal surgery or sub urethral slings. Translabial ultrasound has been utilized for the assessment of central and posterior compartment as well. ${ }^{15}$ The bladder neck or the leading edge of a cystocele is used for the quantification of anterior vaginal wall descent, the cervix or pouch of douglas or the central compartment and the most caudal aspect of the rectal ampulla or the leading edge of rectocele.

The inferior margin of the symphysis pubis anchors a horizontal line of reference against which descent can be measured. In women with isolated posterior compartment prolapse descent of the rectal ampulla or of rectocele contents of $15 \mathrm{~mm}$ below the symphysis seems to be associated with symptoms of prolapse and has been proposed as a cutoff for significant descent on the basis of receiver operator curve characteristics. (Fig. 7, 8)

Anterior rectocele correlations between clinical prolapse grading and ultrasound may not be quite as good for the posterior compartment as they are for cystocele or uterine descent, but it is possible to distinguish between "true" and "false" rectocele. The traditional distinction among low, midlevel and high rectocele is not supported by ultrasound data. One of the main advantages of translabial ultrasound is the ease with which rectocele can be distinguished from enterocele. ${ }^{14}$ However, the method is also capable of demonstrating symptomatic rectal prolapse.

To summarize in our study of 50 cases of pelvic floor dysfunction we found pelvic floor ultrasound is fairly sensitive modality to evaluate bladder neck descent, uterine descent, rectocele and enterocele. Clinical examination and ultrasound examination co related well in our study group. Even though there is no definition for normal or abnormal bladder neck descent we found that patients who had bladder neck movement between 9.5 to $13.4 \mathrm{~mm}$ were significant to be called as cystocele. 
In the central and the posterior compartment we have taken the $14.8-19.8 \mathrm{~mm}$ as the standard level of cut off which suggests that any patient with the cervix crossing the inferior pubic line and a movement of 14.8 and $19.5 \mathrm{~mm}$ can be termed as uterine descent. We have taken 2.8 $5.8 \mathrm{~mm}$ as the standard level of cut off which suggests that any patient with the rectum crossing the inferior pubic line and the movement of $2.8-5.8 \mathrm{~mm}$ can be termed as rectocele.

\section{REFERENCES:}

1. Olsen A, Smith VJ, Bergstorm JO, et al. Epidemiology of surgically managed pelvic organ prolapse and urinary incontinence. Obstet Gynecol 1997; 89:501- 506.

2. Tunn R and Petri E. Introital and transvaginal ultrasound as a main tool in the assessment of urogenital and pelvic floor dysfunction: an imaging panel and practical approach, ultrasound. Obstet Gynecol 2003; 22: 205-213.

3. White RD, Mc Quown D, McCarthy TA, Ostergard DR. Real-time ultrasonography in the evaluation of urinary stress incontinence. Am J Obstet Gynecol 1980; 138 (2): 235-237.

4. Bergman A, Mc Kenzie CJ, Richmond J, Ballard CA, Platt LD. Transrectal ultrasound versus cystography in the evaluation of anatomical stress urinary incontinence. Br J Urol 1998; 62 (3): 228-234.

5. Quinn MJ, Beynon J, Mortensen NJ, Smith PJ. Transvaginal endosonography: a new method to study the anatomy of the lower urinary tract in urinary stress incontinence. Br J Urol 1998; 62(5): 414-418.

6. Dietz HP. Ultrasound imaging of the pelvic floor, Part I: Two Dimensional Aspects. Ultrasound Obstet Gynecol 2004: 23: 80-92.

7. James R. Scott, Steven G. Gebbe. Pelvic Organ Prolapse: New Developments. Clin Obstet Gynecol (Indian edition) 2006; 2 (2):

8. Parks AG, Porter NH, Melzak J. Experimental study of the reflex mechanisms controlling muscles of the pelvic floor. Dis Colon Rectum. 1962; 5: 407-414.

9. Dietz HP. Why Pelvic Floor Surgeons Should Utilize Ultrasound Imaging. Ultrasound Obstet Gynecol 2006; 28: 629-634.

10. Berglas B, Rubin IC. Study of the supportive structures of the uterus by levator myography. Surg Gynecol Obstet 1953; 97: 677-692.

11. Swift SE, Tate SB, Nicholas J. Correlation of symptoms with degree of pelvic organ support in a general population of women: What is pelvic organ prolapse? Am J Obstet Gynecol 2003; 189: 372-379.

12. Weber AM, Walters MD, Ballard LA, et al. Posterior vaginal prolapse and bowel function. Am J Obstet Gynecol. 1998; 179: 1446-1449.

13. Dietz HP, Wilson PD. Anatomical assessment of the bladder outlet and proximal urethra using ultrasound and video cystourethrography. Int Urogynecol J 1998; 9 (6): 365 -369.

14. Dietz HP, Steensma AB. The role of childbirth in the aetiology of rectocele. Br J Obstet Gynecol 2006; 13: 264-267.

15. Creighton SM, Pearce JM, Stanton SL. Perineal video-ultrasonography in the assessment of vaginal prolapse: early observations. Br J Clin Obstet Gynecol 1992; 99 (4): 301-313.

16. Dietz HP, Lennox PJ. Hoyte Anneke B. Steeusma. Atlas of the pelvic floor ultrasound. The central and posterior compartments 2008: pg 70-71. 


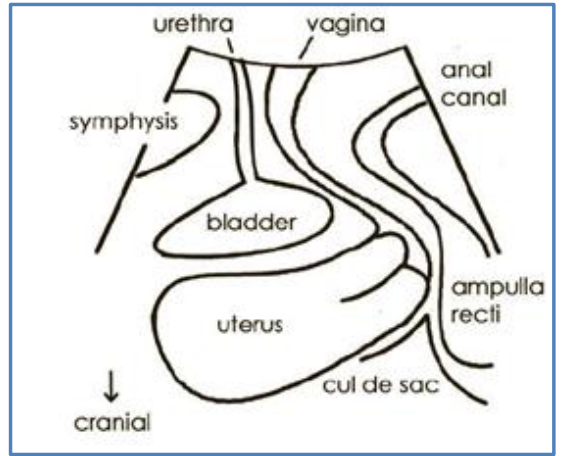

\section{Figure 1}

Figure 1: Field of view in the mid sagittal plane when using a curved array transducer designed for abdominal or obstetric applications.

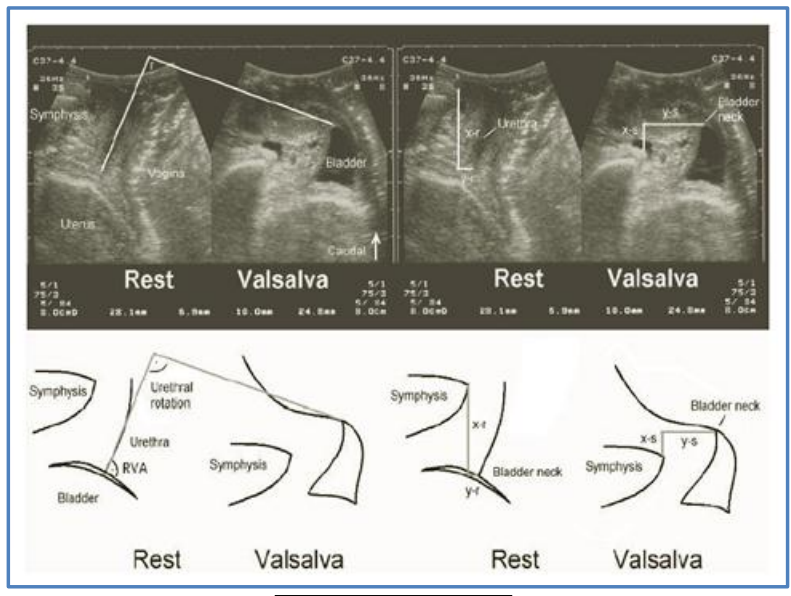

\section{Figure 2}

Figure 2: Marked increase in bladder neck mobility after vaginal delivery
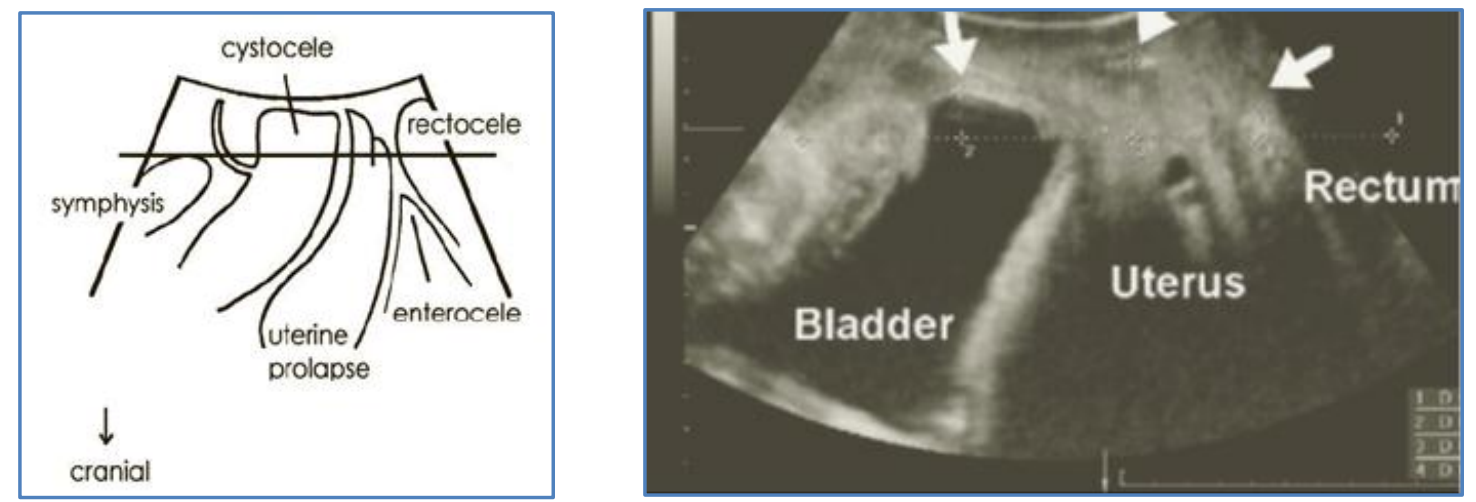

\section{Figure 3}

Figure 3: Prolapse quantification by transperineal ultrasound. Measurements are against a horizontal line through the inferior margin of the symphysis pubis. Clinically there is a second-degree cystocele and second-degree uterine prolapse. 
REVIEW ARTICLE

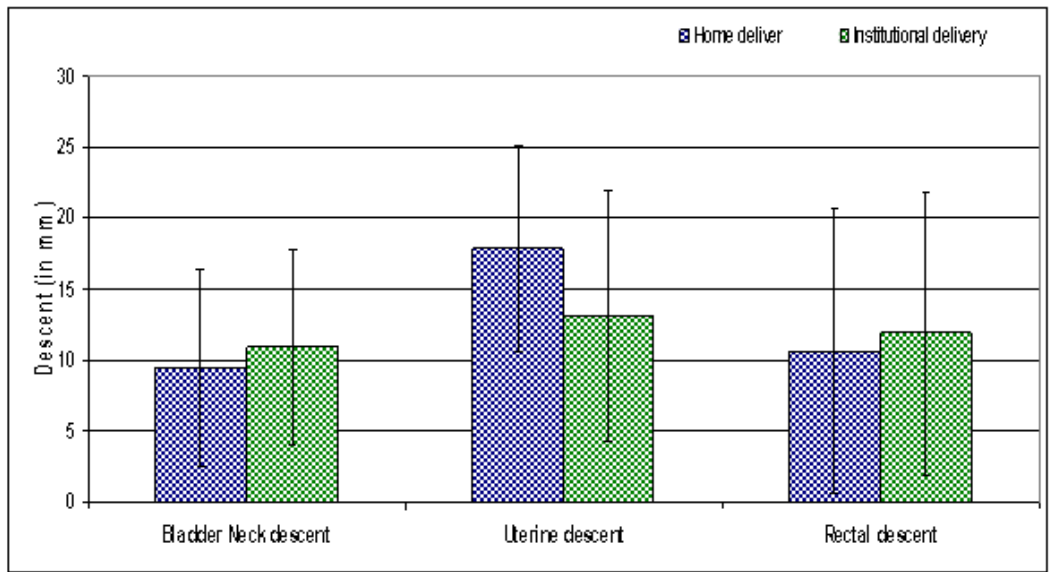

Figure 4: Mean descent recorded in the study sample

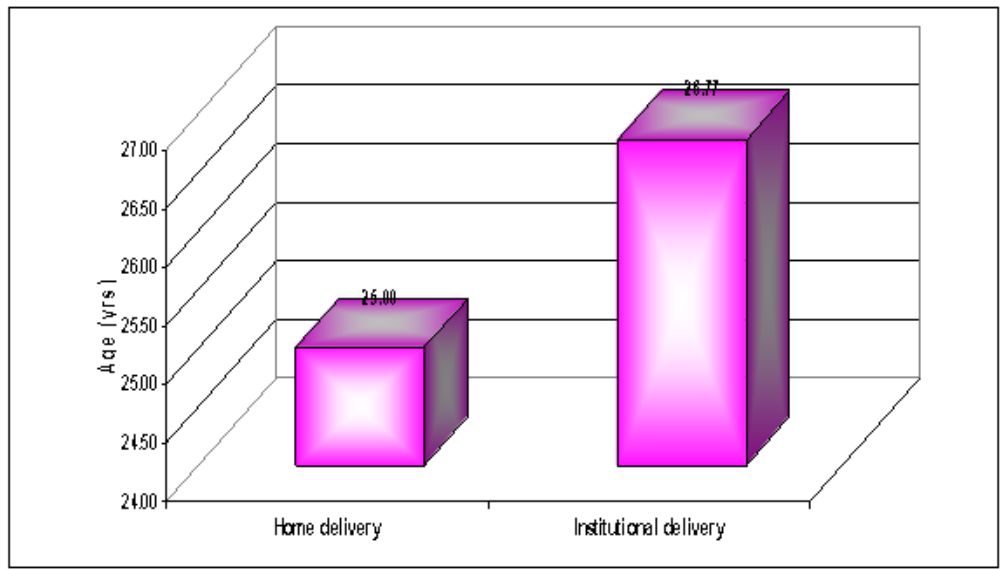

Figure 5: Mean age at last child birth according to mode of delivery

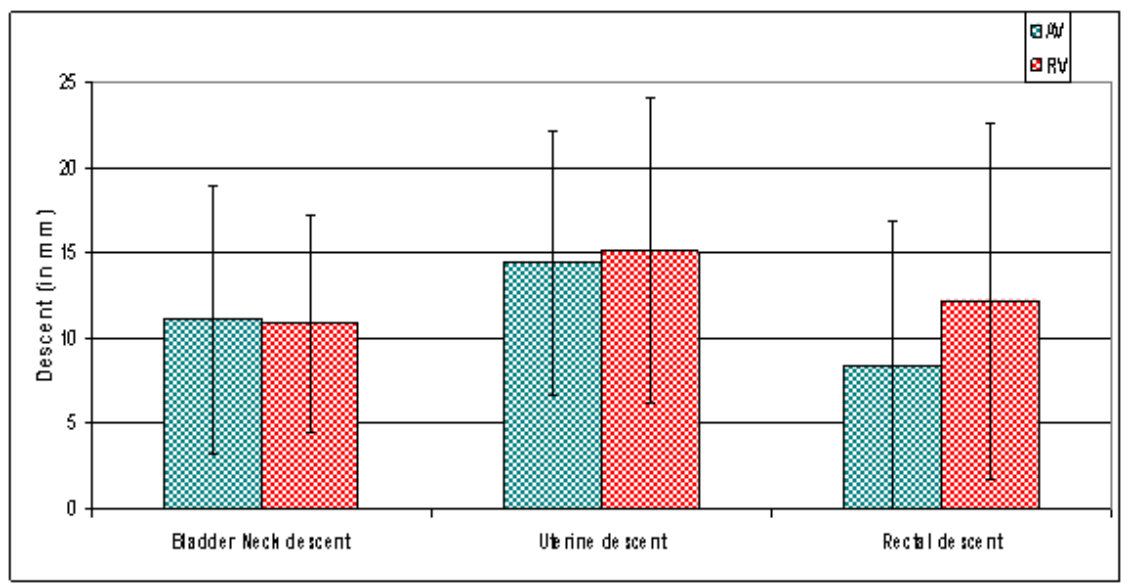

Figure 6: Mean descent recorded in the study sample 


\section{REVIEW ARTICLE}

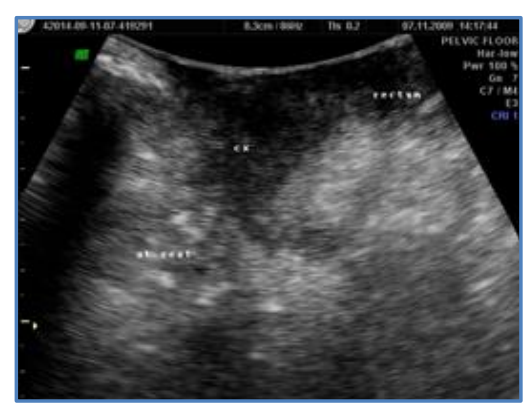

Figure 7 (A)

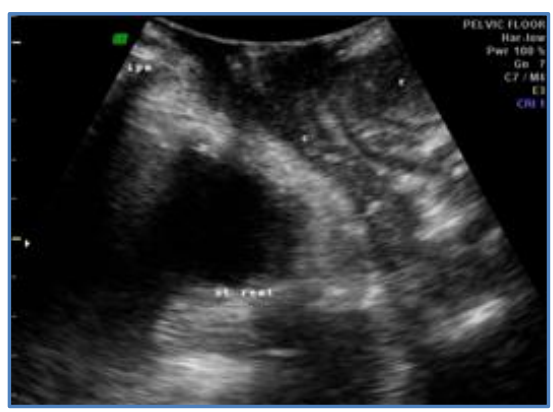

Figure 7 (A)

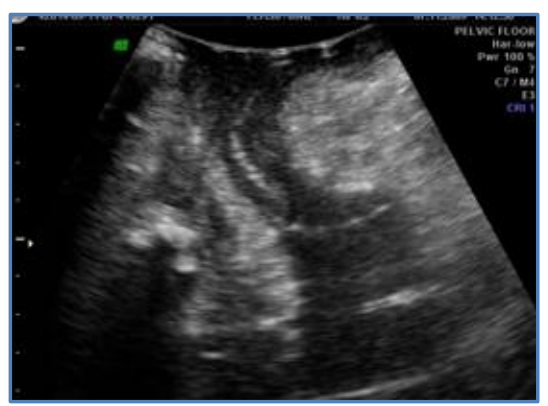

Figure 7 (B)

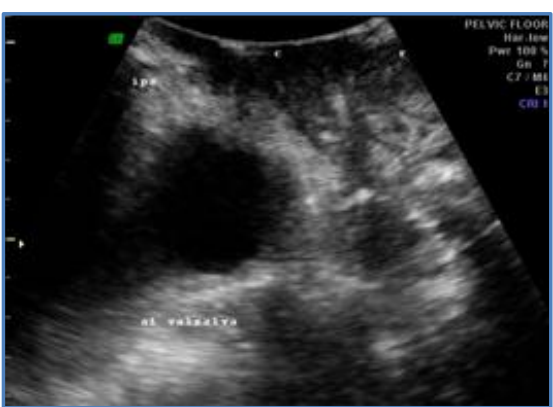

Figure 7 (B)

Figure 7: Mid sagittal transperineal ultrasound showing bladder (B), inferior pubic symphysis (IPS), cervix (C), rectum (R), vagina (V) at rest (A) and Valsalva (V).

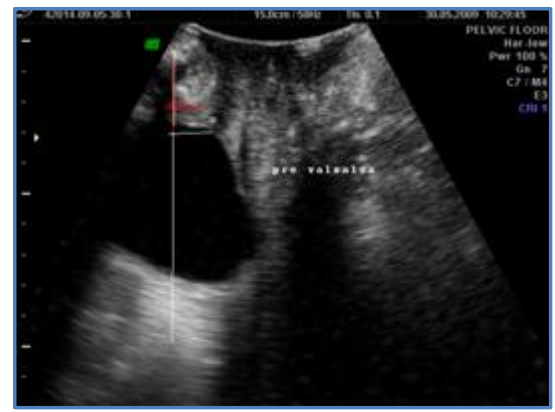

Figure 8 (A)

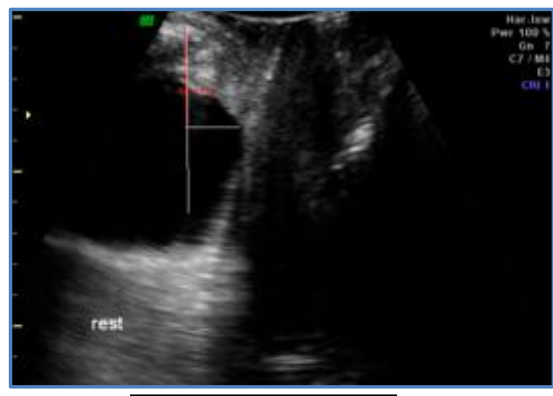

Figure 8 (A)

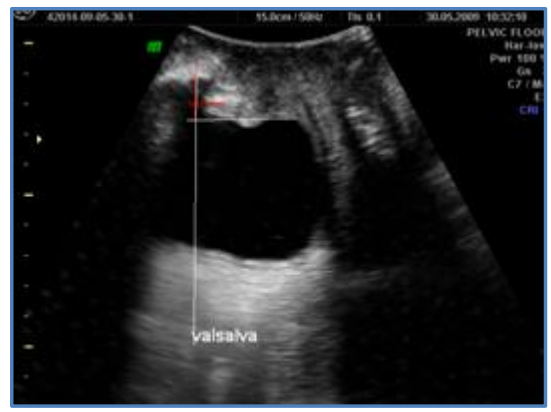

Figure 8 (B)

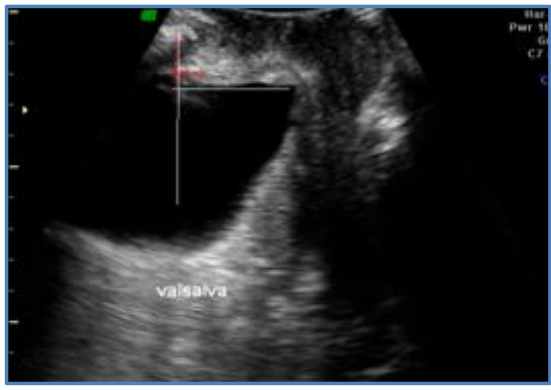

Figure 8 (B)

Figure 8: Transperineal ultrasound showing bladder neck descent at rest (A) and valsalva (B). 


\begin{tabular}{|c|c|c|c|c|c|c|c|}
\hline Parameter & $\begin{array}{l}\text { Mode of } \\
\text { delivery }\end{array}$ & $\mathbf{n}$ & Mean & Std dev & $\begin{array}{c}\text { Mean } \\
\text { difference }\end{array}$ & $\mathbf{t}$ & p-Value \\
\hline \multirow{2}{*}{$\begin{array}{l}\text { No. of times } \\
\text { conceived }\end{array}$} & Home delivery & 25 & 4.48 & 1.29 & \multirow[b]{2}{*}{0.662} & \multirow[b]{2}{*}{1.771} & \multirow[b]{2}{*}{0.083} \\
\hline & $\begin{array}{l}\text { Institutional } \\
\text { delivery }\end{array}$ & 22 & 3.82 & 1.26 & & & \\
\hline \multirow{2}{*}{$\begin{array}{l}\text { Age at last } \\
\text { child birth } \\
\text { (yrs) }\end{array}$} & Home delivery & 25 & 25.00 & 2.92 & \multirow[b]{2}{*}{-1.773} & \multirow[b]{2}{*}{$\begin{array}{c}- \\
1.901\end{array}$} & \multirow[b]{2}{*}{0.064} \\
\hline & $\begin{array}{l}\text { Institutional } \\
\text { delivery }\end{array}$ & 22 & 26.77 & 3.48 & & & \\
\hline \multirow{2}{*}{$\begin{array}{l}\text { Bladder Neck } \\
\text { Descent (mm) }\end{array}$} & Home delivery & 25 & 9.42 & 6.99 & \multirow[b]{2}{*}{-1.466} & \multirow[b]{2}{*}{$\begin{array}{c}- \\
0.724\end{array}$} & \multirow[b]{2}{*}{0.473} \\
\hline & $\begin{array}{l}\text { Institutional } \\
\text { delivery }\end{array}$ & 22 & 10.88 & 6.85 & & & \\
\hline \multirow{2}{*}{$\begin{array}{l}\text { Uterine } \\
\text { Descent (mm) }\end{array}$} & Home delivery & 21 & 17.85 & 7.28 & \multirow[b]{2}{*}{4.721} & \multirow[b]{2}{*}{1.908} & \multirow[b]{2}{*}{0.063} \\
\hline & $\begin{array}{l}\text { Institutional } \\
\text { delivery }\end{array}$ & 22 & 13.13 & 8.82 & & & \\
\hline \multirow{2}{*}{$\begin{array}{l}\text { Rectal Descent } \\
(\mathrm{mm})\end{array}$} & Home delivery & 23 & 10.62 & 9.97 & \multirow[b]{2}{*}{-1.250} & \multirow[b]{2}{*}{$\begin{array}{c}- \\
0.397\end{array}$} & \multirow[b]{2}{*}{0.693} \\
\hline & $\begin{array}{l}\text { Institutional } \\
\text { delivery }\end{array}$ & 18 & 11.87 & 10.04 & & & \\
\hline
\end{tabular}

\begin{tabular}{|l|c|c|}
\hline \multicolumn{1}{|c|}{ Mode of delivery } & $\mathbf{n}$ & $\mathbf{\%}$ \\
\hline Home delivery & 25 & 50.00 \\
\hline LSCS & 3 & 6.00 \\
\hline Institutional delivery & 22 & 44.00 \\
\hline \multicolumn{1}{|c|}{ Total } & $\mathbf{5 0}$ & $\mathbf{1 0 0}$ \\
\hline \multicolumn{1}{|c|}{ Tal }
\end{tabular}

Table 2: Mode of delivery

\begin{tabular}{|l|c|c|c|c|c|c|c|c|}
\hline $\begin{array}{c}\text { Mode of } \\
\text { delivery }\end{array}$ & $\mathbf{n}$ & Mean & Std dev & Min & $\begin{array}{c}\text { 25th } \\
\text { Percentile }\end{array}$ & Median & $\begin{array}{c}\text { 75th } \\
\text { Percentile }\end{array}$ & Max \\
\hline Home Delivery & 25 & 9.42 & 6.99 & 0.20 & 2.95 & 8.60 & 13.35 & 25.00 \\
\hline LSCS & 3 & 14.70 & 5.36 & 10.40 & 10.40 & 13.00 & 20.70 & 20.70 \\
\hline $\begin{array}{l}\text { Institutional } \\
\text { Delivery }\end{array}$ & 22 & 10.88 & 6.85 & 1.60 & 5.95 & 9.25 & 14.65 & 24.20 \\
\hline
\end{tabular}

Table 3: Bladder neck descent according to mode of delivery in the study sample

\begin{tabular}{|c|c|c|c|c|c|c|c|c|}
\hline n & Missing & Mean & Std dev & Min & 25th Percentile & Median & 75th Percentile & Max \\
\hline 32 & 18 & 13.75 & 7.68 & 0.00 & 8.20 & 14.85 & 19.18 & 26.20 \\
\hline \multicolumn{8}{|c|}{ Table 4: Uterine descent in the study sample } \\
\hline
\end{tabular}




\begin{tabular}{|c|c|c|c|c|c|c|c|c|}
\hline n & Missing & Mean & Std dev & Min & 25th Percentile & Median & 75th Percentile & Max \\
\hline 42 & 8 & 10.94 & 9.89 & 0.20 & 2.65 & 7.25 & 22.85 & 28.90 \\
\hline \multicolumn{7}{|c|}{ Table 5: Rectal descent in the study sample } \\
\hline
\end{tabular}

\begin{tabular}{|c|c|c|c|c|}
\hline & Home delivery & \multicolumn{2}{|c|}{ Institutional delivery } & \\
\hline Bladder Neck descent & 9.416 & 10.88182 & 6.9948 & 6.854518 \\
\hline Uterine descent & 17.85238 & 13.13182 & 7.283036 & 8.82477 \\
\hline Rectal descent & 10.62174 & 11.87222 & 9.965849 & 10.04419 \\
\hline
\end{tabular}

Table 6: Mean descent recorded in the study sample

\begin{tabular}{|l|c|c|c|c|}
\hline & AV & RV & & \\
\hline Bladder neck descent & 11.04375 & 10.91667 & 7.821506 & 6.340243 \\
\hline Uterine descent & 14.375 & 15.13667 & 7.737571 & 8.841223 \\
\hline Rectal descent & 8.357143 & 12.1625 & 8.44755 & 10.4187 \\
\hline
\end{tabular}

Table 7: Mean descent recorded in the study sample

\section{AUTHORS:}

1. S. C. Sanjay

2. N. Krishnappa

3. Anil Kumar Shukla

\section{PARTICULARS OF CONTRIBUTORS:}

1. Assistant Professor, Department of Radiodiagnosis, Kempegowda Institute of Medical Sciences, K. R. Road, V. V. Puram, Bangalore.

2. Professor and HOD, Department of Radiodiagnosis, Kempegowda Institute of Medical Sciences, K. R. Road, V. V. Puram, Bangalore.
3. Professor, Department of Radiodiagnosis, Kempegowda Institute of Medical Sciences, $\mathrm{K}$. R. Road, V. V. Puram, Bangalore.

\section{NAME ADDRESS EMAIL ID OF THE} CORRESPONDING AUTHOR:

Dr. Anil Kumar Shukla, \#77, Himagiri Apartment,

Flat 4C, $15^{\text {th }}$ Cross, $4^{\text {th }}$ Main,

Malleswaram, Bangalore - 560055 .

E-mail: shookla2007@yahoo.co.in

Date of Submission: 26/03/2014. Date of Peer Review: 27/03/2014. Date of Acceptance: 12/04/2014. Date of Publishing: 05/05/2014. 